\title{
2 Macabeus e os cânones grego, judaico e cristão*
}

\section{Maccabees and the Greek, Jewish and Christian canons \\ 2 Macabeos y los cánones griego, judío y cristiano}

Willibaldo Ruppenthal Neto*

\begin{abstract}
RESUMO
O presente artigo visa analisar a relação do livro de 2 Macabeus com os cânones grego (LXX), judaico (Bíblia Hebraica) e cristão (das diversas denominações). Além de se averiguar a relevância do livro para a história do judaísmo, se destaca a relação com os cânones como evidência de sua importância teológica e de sua difusão no contexto helenístico.

Palavras-chave: 2 Macabeus; cânon; judaísmo; Septuaginta (LXX); Bíblia.
\end{abstract}

\begin{abstract}
This article aims to analyze the relationship between the book of 2 Maccabees and the Greek (LXX), the Jewish (Hebrew Bible) and the Christian (of the various denominations) canons. In addition, aims to ascertain the relevance of the book to the history of Judaism, showing the relation with the canons as evidence of its theological importance and its diffusion in the Hellenistic context.

Keywords: 2 Maccabees; canon; Judaism; Septuagint (LXX); Bible.

\section{RESUMEN}

El presente artículo busca analizar la relación del libro de 2 Macabeos con los cánones griego (LXX), judío (Biblia hebrea) y cristiano (de las diversas denominaciones). Además, busca también averiguar la relevancia del libro para la historia del judaísmo, destacando la relación con los cánones como evidencia de su importancia teológica y de su difusión en el contexto helenístico.

Palabras clave: 2 Macabeos; canon; judaísmo; Septuaginta (LXX); Biblia.
\end{abstract}

Tendo tamanha importância histórica, como uma das principais fontes da Revolta dos Macabeus, e construindo-se dentro de um esquema teológico diretamente conectado à Bíblia Hebraica, não foi à toa que 2 Macabeus veio a fazer parte da Septuaginta (LXX) - a primeira tradução grega dos livros sagrados judaicos -, mesmo que posteriormente não tenha estado presente no cânon rabínico.

Quanto à Septuaginta (LXX), sua formação é, em certa medida, permeada de lendas e teorias. Segundo a Carta de Aristeas, por exemplo, a

\footnotetext{
* O presente artigo é parte de minha dissertação de Mestrado em História, defendida em 2018 (contando com bolsa do CNPq) na UFPR, com modificações.

** Doutorando em História (PPGHIS/UFPR). Professor das FABAPAR e membro discente do NEMED/ UFPR. E-mail: willibaldoneto@hotmail.com
} 
LXX teria sido um empreendimento de tradução cuja iniciativa partiu de Ptolomeu II, rei do Egito, o qual solicitou ao sumo sacerdote Eleazar que seis anciãos de cada tribo fossem enviados ao Egito, a fim de realizarem a tradução dos textos sagrados judaicos. Tal tradição legendária ganhou espaço não somente dentro da religiosidade judaica, mas também entre os estudiosos. Elias Bickerman (2007, p. 108-133 [1]), por exemplo, mesmo que negue a autenticidade da Carta de Aristeas, defende esta tradição. Segundo ele, as grandes traduções na Antiguidade eram empreendimentos públicos, sendo a LXX um exemplo dentre outros.

Arnaldo Momigliano, no entanto, apesar de admitir a situação para traduções para o latim, incentivadas por Roma ${ }^{1}$, evita aplicar o mesmo aos gregos. Para ele, a LXX é resultante da iniciativa privada judaica, decorrente da perda da importância do hebraico, a qual criou uma necessidade de uma tradução dos textos religiosos para o grego tanto para o culto religioso como para a leitura privada (MOMIGLIANO, 1975a, p. 90). A LXX, portanto, não teria surgido no palácio de Alexandria, mas antes "nasceu dentro dos recintos da sinagoga” (MOMIGLIANO, 1975a, p. 91-92).

Se Momigliano estiver correto, pode-se inclusive supor que haveria uma tradução grega anterior à LXX, pelo menos de algumas partes da Torá, como a citação de Deuteronômio 29.1 por Hecateu de Abdera (Aegyptiaka apud Diodoro Sículo, Bib. Hist., 40.3, cf. RUPPENTHAL NETO, 2018, p. 182) parece indicar. A teoria de Momigliano explicaria a razão da peculiaridade da LXX, como "o maior corpus de tradução de toda a Antiguidade", de modo que "em toda a literatura grega não conhecemos outro exemplo de tradução de proporções tão extensas como a Bíblia grega" (FERNANDÉZ MARCOS, 2007, p. 271).

Porém, para além disto, a teoria de Momigliano também ressalta um processo de escolha de textos como sagrados pelos próprios judeus, que realizavam a tradução para o grego a fim de utilizarem de tais traduções na sinagoga. Haveria, portanto, uma formação de um cânon do judaísmo no interior das sinagogas, o qual, porém, não pode ser efetivamente provado.

Como bem indicado por Timothy H. Lim (2013, p. 17-34), não há um consenso entre os estudiosos no que diz respeito à definição do cânon judaico, de modo que, interpretando certos textos antigos como pistas da formação de um cânon, são indicadas as possibilidades de uma definição no final do período persa ou mesmo no período macabeu². Neste sentido, não

\footnotetext{
Cf. Plínio, NH, 18.22.

Cf. Sb (prólogo); 2 Mac 2.13-15; 4Q396, 1s. 10-11; Mt 23.34-36; Lc 24.44; m. Yad 3.5; Josefo, Ap., 1.38-42; Talmude Babilônico, Baba Batra, 14b-15a.
} 
se pode deixar de fora os textos dos manuscritos de Qumran. Porém, não é simples a tarefa de se utilizar os manuscritos do Mar Morto para indicação de formação do cânon (VANDERKAM, 2001b), especialmente quando se percebe que os manuscritos não são somente cópias de obras canônicas, mas também obras de caráter ambíguo e baseadas naquelas (WARREN-ROTHLIN, 2016), cujo valor e validade dentro da comunidade de Qumran é difícil de se definir. Quanto ao texto de 4Q396 10-11, por exemplo, que parece ser o mais evidente neste quesito, autores como Timothy H. Lim (2001) rejeitam a possibilidade de haver uma referência às três partes da Tanakh, ou que haveria sentido de canonicidade.

Ao mesmo tempo, há indícios na literatura judaica além de Qumran. Como indicado por Duane L. Christensen (1986), há a possibilidade de ter havido um cânon judaico com a divisão tripartida, mas menor, com 22 livros (ao invés dos 24 do cânon farisaico), como estaria na lista hebraica-aramaica de Audet, e em Flávio Josefo. Como Jacob Neusner (2003, p. 93) destaca, porém, quando se fala em um "cânon rabínico", compreendendo-se por judaísmo rabínico a forma de judaísmo que passou a vigorar principalmente após 70 d.C., deve-se pensar em um cânon duplo, formado pela Torá escrita (Bíblia Hebraica), e pela Torá oral (juntamente às histórias dos sábios), preservada na m. (c200 d.C.) e no b. (c600 d.C.).

Pode-se dizer, portanto, que fez parte, portanto, do "cânon grego", e não do cânon hebraico massorético, do qual a LXX se difere em diversos aspectos, como os livros incluídos, os títulos dos livros, a sequência destes, e mesmo a organização interna da coleção (JOOSTEN, 2016, p. 698). Mas afinal, no que implica ter feito parte deste cânon de textos judaicos traduzidos para o grego já na Antiguidade no que ficou conhecido como a Septuaginta? E ainda: quais as razões para o livro de 2 Macabeus ser incluído em tal conjunto literário?

Fazer parte desta composição de textos judaicos em grego certamente não foi somente decorrente da ampla leitura da obra, mas também teve como efeito a valorização e difusão da mesma, especialmente entre os judeus dentro e fora da Judeia, mesmo que alguns autores busquem questionar este aspecto (exemplo: BAR-KOCHVA, 1989, p. 67). Deste modo, a ampla leitura da obra é tanto a causa da incorporação naquele cânon como ainda sua consequência, uma vez que a presença em uma coletânea tão importante quanto a LXX deve ter colaborado consideravelmente na divulgação da mesma. Mesmo assim, porém, se costuma afirmar que, sendo uma obra escrita originalmente em grego e datando claramente depois de Alexandre, o Grande, dificilmente seria aceita pelos rabinos dos primeiros séculos da era cristã, mesmo que 
pretendessem uma abertura do farisaísmo aos demais segmentos do judaísmo, tornando Jâmnia em uma sociedade judaica mais aberta.

Quanto ao grego, não há consenso entre os estudiosos. Conforme Daniel Schwartz, "os rabis que definiram o cânon no primeiro e segundo século nunca teriam considerado incluir qualquer coisa obviamente composta em grego" (SCHWARTZ, 2008, p. 57). Segundo Arnaldo Momigliano, porém, a causa seria outra: "o repúdio da história e historiografia pelos judeus depois da destruição do Segundo Templo" (MOMIGLIANO, 1975b, p. 88). De fato, Momigliano argumenta corretamente quando lembra que "1 Macabeus, apesar de escrita originalmente em hebraico (...) compartilhou do destino de 2 Macabeus" (MOMIGLIANO, 1975b, p. 88). Porém, Momigliano parece não perceber a primazia do elemento temporal na definição do cânon judaico.

Segundo o texto do Seder Olam Rabbah (30), até Alexandre, o Grande, "profetas profetizavam pelo espírito santo, mas de agora em diante: emprestem os seus ouvidos e ouçam os Sábios". Daniel Schwartz lembra que alguns textos de 1 Macabeus $(4.46 ; 9.27 ; 14.41)$, assim como de Flávio Josefo (Ap., 1.41) acompanham esta divisão.

É bem possível que esta perspectiva, crescente nos primeiros séculos depois de Cristo, tenha sido fortalecida pela necessidade de reação à perspectiva cristã da continuidade da profecia, na tentativa de vincular a Bíblia Hebraica aos Escritos Cristãos enquanto "Antigo Testamento" (SCHWARTZ, 2008, p. 57, nota 133). Como lembra Frederick E. Greenspahn, rejeitando a presença do "Espírito Santo" em seu tempo, os rabis se protegiam daqueles que afirmavam terem uma conexão mais direta com Deus do que eles (GREENSPAHN, 1989, p. 49).

Mesmo assim, porém, já antes do cristianismo a profecia judaica estava claramente em declínio, dando espaço não somente à escatologia (WILSON, 2006, p. 356), como ainda à exegese (SOMMER, 1996, p. 47). Independentemente do surgimento de figuras proféticas e escatológicas, como Jesus Cristo, é evidente que os judeus estavam bastante inclinados a não aceitarem mais que Deus falasse da mesma forma como no "tempo dos profetas" (SOMMER, 1996) ${ }^{3}$. Greenspahn (1989, p. 37) lembra ainda a intercambialidade entre as expressões "espírito santo" e "espírito de profecia" nos targumim. Assim, o Targum Neofiti de Éxodo 2.12 apresenta "espírito santo" na mar-

\footnotetext{
Sobre o desaparecimento do "Espírito Santo", cf. Toseftá Sotah, 13.2; Talmude de Jerusalém, Sotah, 24b; Talmude Babilônico, Sotah, 48b; Talmude Babilônico, Sanherdrin, 11a; Talmude Babilonico, Yoma, 9b; Cantares Rabbah 8.9. Sobre a relação da inspiração pelo espírito santo e a canonicidade, cf. Toseftá Yadayim, 2.14; Talmude Babilônico, Megillah, 7a.
} 
gem esquerda e "espírito de profecia" na margem direita (GREENSPAHN, 1989, p. 38, nota 5).

Quanto ao caso de Jâmnia, cabe uma palavra importante. Afinal, o que é conhecido como "Concílio de Jâmnia", ou ainda "Concílio de Javné", diferente da imagem construída por H. Graetz, F. Buhl, H. E. Ryle e outros teólogos, não foi propriamente um "concílio", nem teve a pretensão de estabelecer o fechamento do cânon judaico, como se costuma afirmar.

Como bem demonstrado por D. E. Aune (1991), este foi um "mito" estabelecido pela crítica teológica. A usual referência ao texto de m. Yad 3.5 não prova o fechamento do cânon, pois apenas se refere às discussões sobre Cantares e Eclesiastes, que nem mesmo terminaram em Jamnia (LEWIS, 1992, p. 634-637 [III]; 1964). É possível que Jâmnia tenha sido uma tentativa de unificação do judaísmo após a destruição do Templo, indicando antes uma abertura do farisaísmo aos demais grupos, do que o pretenso fechamento do cânon (COHEN, 2010, p. 44-70).

Tal tentativa parece ter sido decorrente de uma diversidade de posições em relação a vários textos. Neste sentido, 2 Macabeus pode ter inclusive dividido visões. Afinal, apesar de ser amplamente lido, deve ter sido também alvo de críticas, até porque havia até mesmo certa aversão por parte de muitos rabinos à $\mathrm{LXX}^{4}$, assim como muitos evitaram dar muito destaque aos macabeus e à dinastia dos Asmoneus que os seguiu, os quais são valorizados não somente no livro de 2 Macabeus como também no livro de 1 Macabeus que, apesar de ter sido escrito originalmente em hebraico, também não entrou no cânon judaico. Deste modo, como bem lembra Stemberger, "é surpreendente quão pouca informação sore os macabeus se pode encontrar nos primeiros escritos rabínicos" (STEMBERGER, 1992, p. 201)5.

Todos estes fatores podem ter pesado na exclusão de 2 Macabeus do cânon judaico. Porém, mesmo para os cristãos, que não tinham tais requisitos como os da língua hebraica e da datação anterior a Alexandre para incluírem um livro no seu cânon, os livros judaicos que ficaram fora da Bíblia

\footnotetext{
4 Ao contrário de algumas supervalorizações da LXX, como na Carta de Aristeas e na obra de Filo (p.e.: Filo, Vit. Mos., 2.37), diversos textos rabínicos hostilizam a versão grega, não somente indicando seus erros (Talmude Babilônico, Megillah, 9a; Talmude de Jerusalém, Megillah, 1,1,4; Mekbilta de Rabbi Ishmael de Êx 12.40; Midrash HaGadol de Êx 4.20; Abot de Rabbi Nathan, versão B, cap. 37; Yalkut Shimoni de Gn 3; Midrash Tanhuma de Êx \$22), como ainda afirmando que o dia de sua tradução foi "um dia tão abominável para Israel quanto o dia da confecção do bezerro de ouro” (Masekhet Soferim 1.7).

5 Sobre as referências rabínicas aos macabeus, cf. STEMBERGER, 1992; Talmude Babilônico, Megillah, 1.6 (70c); Talmude Babilônico, Ta’anit, 2.13 (66a); Talmude Babilônico, Táanit, 18b. Sobre as referências rabínicas aos asmoneus, cf. Talmude Babilônico, Shabbat, 21b; Talmude Babilônico, Berakhot, 48a; Talmude Babilônico, Menahot, 64b; Talmude Babilônico, Qiddushin, 70a-b; Talmude de Jerusalém, Ta'anit, 2.12.
} 
Hebraica (dentre os quais 2 Macabeus) foram tratados com certa cautela, apresentando-se de forma problemática, sendo colocados ao fim ou mesmo estando ausentes de diversas listas canônicas ao longo da história cristã. Por esta razão, estes livros foram uma causa de discussão e diferenciação no cristianismo, de modo que tais obras atualmente são consideradas como "deuterocanônicas", estando presentes na Bíblia Católica e na Bíblia Ortodoxa, ou como "apócrifas", como são denominadas pelos protestantes, que não as incluem no seu cânon.

O termo "deuterocanônico" provém das raízes gregas deuteros

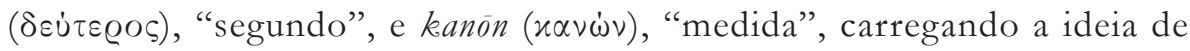
livros que foram canonizados em um segundo momento. Como indicado por Gilles Dorival, apesar desta expressão ter ficado famosa pelo Concílio de Trento (1545-1563), que reafirmou a validade de tais livros - em oposição ao protestantismo nascente que os negou -, não foi criada neste concílio, mas já antes foi utilizada por Sixtus de Siena, um judeu convertido ligado ao concílio (DORIVAL, 2007, p. 1-10). Na realidade, o Concílio de Trento em boa medida reafirmou a definição que já estava vigente, do valor sagrado destes textos. São eles: Tobias, Judite, 1 Macabeus, 2 Macabeus, Sabedoria de Salomão, Eclesiástico, Baruque e Tobias. Há ainda algumas passagens adicionais a livros presentes no cânon judaico, como Daniel, Ester e Salmos.

O termo "apócrifos", porém, provém da palavra grega apókryphos

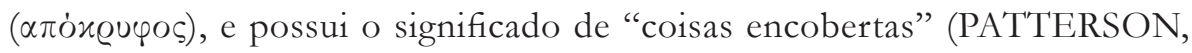
1992, p. 292 [T]). Originalmente, se referia aos "livros contendo ensinamentos ocultos que não devem ser descobertos por pessoas ordinárias" (OESTERLEY, 1935, p. 4), sendo obras de grupos sectários, sendo conhecidas dentro do círculo de crentes. Os protestantes, porém, utilizam o termo para se referir aos livros tidos por católicos e ortodoxos como "deuterocanônicos" (VANDERKAM, 2001a, p. 54-55). Este uso não foi invenção protestante, mas remonta a Jerônimo, que assim os denominava. Porém, cabe se destacar que, apesar de Jerônimo designar os livros deuterocanônicos como "apócrifos" (GOODMAN, 2001), também os chamava de libri ecclesiastici, "livros da igreja" (BARTLETT, 1998, p. 13).

Mesmo que os livros ditos "deuterocanônicos" ou "apócrifos" sejam mais recentes do que os livros inclusos na Bíblia Hebraica, formam certa unidade com estes, uma vez que não só completam o relato bíblico (apresentando a história subsequente), mas também dão continuidade àqueles textos, fazendo alusões e colocando-se na mesma "história de salvação". Assim, estando entre o que os cristãos entendem por "Antigo Testamento" e "Novo Testamento", Jerônimo os entende como sendo também "livros da igreja". 
Deste modo, os heróis da Revolta dos Macabeus, como Judas Macabeu, se assemelham aos heróis bíblicos, como Neemias, tanto em seus feitos como no cuidado com o registro e preservação dos acontecimentos relativos ao povo judeu, como se pode perceber em 2 Macabeus 2.13-14:

Também nos documentos e nas Memórias de Neemias eram narradas essas coisas. E, além disso, como ele, fundando uma biblioteca, reuniu os livros referentes aos reis e aos profetas, os escritos de Davi e as cartas dos reis sobre as oferendas. Da mesma forma, também Judas recolheu todos os livros que tinham sido dispersos por causa da guerra que nos foi feita, e eles estão em nossas mãos. (2 Mac 2.13-14; cf. BÍBLIA DE JERUSALÉM).

Ambos, Judas e Neemias, percebem a importância da reunião dos textos da história judaica, elemento essencial na constituição da identidade deste povo. É bem possível também que tal texto de 2 Macabeus seja um indício do processo de formação do cânon judaico já no período helenístico próximo à Revolta dos Macabeus. O texto de 2 Macabeus citado, porém, deixa laços a serem desembaralhados pelos estudiosos, especialmente no que diz respeito às expressões "os livros referentes aos reis e aos profetas" e "os escritos de Davi".

Apesar da expressão "os livros referentes aos reis e aos profetas"

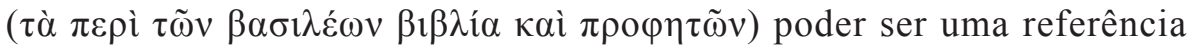
aos "livros dos Profetas" (םיאירְְנ) e aos livros históricos, que compõem os "Escritos" (םיבוּרְּ), Stefan Schorch vai contra esta ideia: "é muito improvável que a designação [...] realmente signifique os livros históricos e proféticos que se tornaram parte do cânon judaico" (SCHORCH, 2007, p. 171; BORCHARDT, 2015, p. 190). De fato, a expressão parece carregar implicitamente a ideia de "sobre os profetas" ([ $\pi \varepsilon \rho i] \pi \rho \circ \varphi \eta \tau \tilde{\omega} \nu)$, aparentemente se referindo aos livros escritos a respeito da vida dos profetas, a exemplo dos "registros"

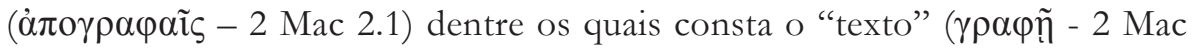
2.4) sobre a vida do profeta Jeremias, cuja tradição apócrifa é bastante diferente do livro bíblico de Jeremias, sendo utilizada em 2 Macabeus 2.1-7.

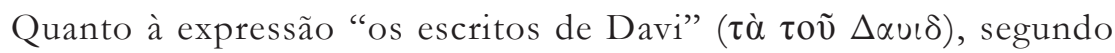
Stefan Schorch, esta não deve ser tomada como uma indicação do Saltério (Salmos), como pode parecer. Apesar de Davi ser de fato o maior entre os autores do livro de Salmos, não é o único, assim como também os Salmos não são sua única obra. O significado de $\tau$ à $\tau o \tilde{v} \Delta \alpha u \iota \delta$ em 2 Macabeus 2.13

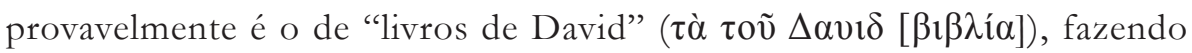
referência às outras obras que teria escrito. De fato, segundo 11QPS 1 17.2-

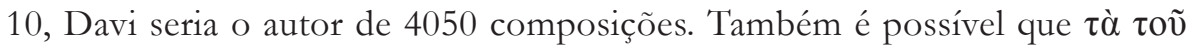




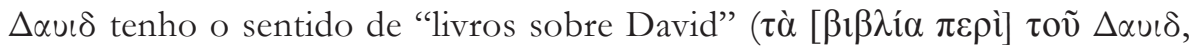
cf. SCHORCH, 2007, p. 171).

Para além destes aspectos, o texto também é enigmático a respeito do que quer dizer com "biblioteca". Afinal, levando-se em conta que, segundo Sextus Pompeius Festus (De verb. sig. apud LANGE, 2007, p. 56), pode-se compreender por biblioteca (bibliotheca), "tanto um grande número de livros quanto o local onde são guardados" (tam librorum magnus per se numerus, quam locus ipse), não fica claro o que o texto de 2 Macabeus quer dizer por "bi-

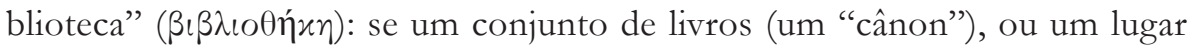
onde estes eram depositados (LANGE, 2007, p. 155-167).

Assim, apesar de autores como Armin Lange (2007) e Stefan Schorch (2007) irem contra o uso deste texto com o propósito de afirmar uma datação antiga do cânon judaico, S. Z. Leiman (1976, p. 28-30), R. T. Beckwith (1985, p. 356; 1988, p. 57-58), Ian Young (2002, p. 388), e, principalmente, A. Van der Kooij (1998), indicam a possibilidade, baseados neste e em outros textos, da existência de um cânon tripartido já no período macabeu, do qual o texto de 2 Macabeus 2.13-14 é uma evidência literária importante.

Seja como for, apesar de não estar clara a importância que a "biblioteca" de Neemias mencionada teve para o processo de canonização dos textos sagrados judaicos, se pode perceber o valor dado pelos judeus (desde os tempos bíblicos), para a preservação de sua história e o registro da mesma. Tanto 1 Macabeus como 2 Macabeus tiveram grande importância: sendo as principais fontes a respeito da Revolta dos Macabeus, que entrou para a história judaica como um período exemplar, digno de lembrança e comemoração, possuíram um valor diferencial, que as levou a serem incluídas na Septuaginta, em algumas Bíblias cristãs e, claro, serem amplamente lidas no meio judaico atual, mesmo que como fontes históricas e não como textos sagrados.

Porém, cabe uma última explicação sobre os livros dos Macabeus. Diferente do que se tende a pensar em decorrência da nomenclatura de 1 Macabeus e 2 Macabeus, estes livros não são somente independentes como também diferentes, apresentando a Revolta dos Macabeus por perspectivas bastante distantes, e até mesmo conflitantes em alguns pontos. De fato, alguns autores tais como George W. E. Nickelsburg (1971) e Jonathan A. Goldstein (1976, p. 64-89; 1983, p. 17-19, 82-83), procuram enfatizar estas diferenças, destacando se tratar de dois livros que contam a mesma história com propósitos não somente diferentes, mas divergentes e competidores (RUPPENTHAL NETO, 2017).

Assim, apesar dos seus títulos serem de fato adequados por ambos os livros tratarem da Revolta dos Macabeus, podem causar certo mal-entendi- 
do, dando a entender uma continuidade que não existe. Ambos os títulos provêm dos manuscritos gregos que, em geral, nomeiam os livros como

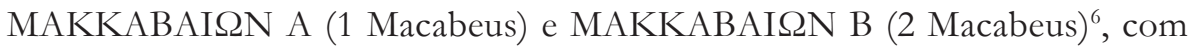
propósito principal de organização dentro dos textos judaicos, colocando uma obra após a outra e, por isso, numerando-as. Trata-se, portanto, de obras relacionadas pela organização dos livros da LXX, sem que por isso sejam semelhantes ou decorrentes.

Além de 1 Macabeus cobrir um total de 40 anos de relato ${ }^{7}$ enquanto 2 Macabeus não chegar a $20 \operatorname{anos}^{8}$, as interpretações também mudam consideravelmente. 2 Macabeus, portanto, não é de modo algum uma continuação de 1 Macabeus. Da mesma forma, o livro denominado 3 Macabeus não é continuação de 2 Macabeus - na verdade, este livro nem mesmo trata da Revolta dos Macabeus, sendo assim intitulado por ser normalmente apresentado após 2 Macabeus.

Nem por isso se pode afirmar que não há qualquer relação entre os dois livros. Afinal, há quem defenda inclusive uma conexão direta entre 2 Macabeus e 3 Macabeus. C. W. Emmet, por exemplo, chega a afirmar que "a impressão que fica é que ambos os livros pertencem à mesma escola de pensamento, e provavelmente ao mesmo período" (EMMET, 1913, p. 156-157 [I]). Johannes Tromp (1995), por exemplo indica 2 Macabeus como fonte de 3 Macabeus, destacando o relato de Heliodoro, presente não somente em 2 Macabeus (capítulo 3), mas também em 3 Macabeus (capítulos 1-2), para além de outras semelhanças entre os dois livros tais como a intenção apologética de ambos, a inclusão de cartas oficiais, além do relato a respeito de Eleazar (DIEZ MACHO, 1984, p. 202-203, nota 1).

De modo semelhante o livro intitulado 4 Macabeus, apesar de não ter a revolta como tema - não justificando seu título -, se relaciona com 2 Macabeus, retomando e aprofundando os relatos de martírio que estão neste outro livro (capítulos 6-7), e fazendo eco a este, apesar de ser bastante posterior. Afinal, segundo Elias Bickerman (2007, p. 266-271), 4 Macabeus seria uma obra escrita entre 20 e 54 d.C., por volta do ano 35 d.C., sendo contemporânea de alguns escritos de Filo e mesmo de Paulo, e, portanto, bem posterior

\footnotetext{
6 A designação M $\alpha \varkappa x \alpha \beta \alpha i \omega \nu \beta$ se encontra nos unciais Cod. A e Cod. V, e é seguido por todos os cursivos, cf. OESTERLEY, 1935, p. 315. Quanto ao texto, apesar de estar completo no Cod. A, se apresenta fragmentário no Cod. V e nem mesmo consta no Cod. $\times$.

Começando com a perseguição de Antíoco Epifânio (175 a.C.), vai até a morte de Simão (134 a.C.), totalizando quarenta anos completos (uma geração).

8 Apesar de iniciar em um período anterior a 1 Macabeus, no final do reinado de Seleuco IV, somente avança até a derrota de Nicanor, correspondendo somente ao que é apresentado nos capítulos de 1 a 7 de 1 Macabeus.
} 
a 2 Macabeus. 4 Macabeus, portanto, apesar de não dar continuidade a 2 Macabeus em relação ao relato, no que diz respeito à história da Revolta dos Macabeus, lhe dá continuidade como interpretação, aprofundando questões deixadas em aberto a respeito do martírio.

No que diz respeito à canonicidade atual, enquanto 1 Macabeus e 2 Macabeus fizeram parte da Septuaginta (e compõem as Bíblias Católica e Ortodoxa), 3 Macabeus somente foi incorporado nas Bíblias Ortodoxas ${ }^{9}$ e na Bíblia Armênia, e 4 Macabeus na Bíblia da Igreja Ortodoxa Georgiana. Deste modo, apesar de ser possível falar-se nos "livros dos Macabeus" - referindo-se a 1, 2, 3 e 4 Macabeus $^{10}$-, deve-se ter consciência que não se trata de um conjunto homogêneo de textos, mas antes de livros bastante particulares e consideravelmente independentes, cuja presença em diferentes cânones evidencia sua importância não somente histórica mas também teológica.

Assim, apesar de não constar nas Bíblias protestantes, o livro de 2 Macabeus possui uma grande importância histórica e teológica, ao ponto de ser recorrentemente vinculado a outros cânones, a exemplo de sua inclusão no cânone grego (LXX) e no cânone católico.

\section{Referências bibliográficas}

AUNE, D.E. On the Origins of the "Council of Javneh" myth. JBL, Atlanta, GA, vol. 110, n. 3, p. 491-493, 1991.

BAR-KOCHVA, Bezalel. Judas Maccabaens: the Jewish struggle against the seleucids. Cambridge: Cambridge University Press, 1989.

BARTLETT, John R. 1 Maccabees. Sheffield: Sheffield Academic Press, 1998. (Guides to the Apocrypha and Pseudepigrapha).

BECKWITH, R. T. Formation of the Hebrew Bible. In: MULDER, M.J. (Ed.). Mikra: text, translation, reading and interpretation of the Hebrew Bible in ancient Judaism and early Christianity. Assen: Van Gorcum, 1988, p. 40-45.

BECKWITH, R. T. The Old Testament canon of the New Testament church and its background in early Judaism. Grand Rapids: Eerdmans, 1985.

BICKERMAN, Elias J. Studies in Jewish and Christian history. A New Edition in english including the God of the Maccabees. Introduced by Martin Hengel. Edited by Amram Tropper. Leiden; Boston: Brill, 2007. (Ancient Judaism and Early Christianity, 68). 2 Volumes.

\footnotetext{
9 Apesar de estar presente na Bíblia Ortodoxa, é considerado um A A $\alpha \gamma \iota \gamma \nu \omega \sigma x o ́ \mu \varepsilon v \alpha$, um livro "digno de ser lido", mas de valor secundário em relação aos textos canônicos.

10 Tanto Clemente de Alexandria (Strom., 1.21.123) como Orígenes (Cels., 8.46) parecem chamar 1 e 2 Macabeus como T $\alpha$ M $\propto \varkappa \varkappa \alpha \beta \not \ddot{x} \alpha$ ("histórias macabeias”), o que, segundo Goldstein, pode ser uma transformação da designação para todos os heróis da história (GOLDSTEIN, 1983, p. 3). Cf. Eusébio de Cesaréia, Hist. eccles., 6.25.2. De Tertuliano (Adv. Iud., 4) em diante, não somente há esta referência aos heróis como "macabeus", mas também os pais da Igreja chamarão os dois livros de "livros dos macabeus" (M $\alpha \varkappa x \alpha \beta \alpha i \omega \nu \beta \imath \beta \lambda i \alpha)$. Cf. Hipólito, De Ant., 49.
} 
BÍBLIA DE JERUSALÉM. Tradução coordenada por Gilberto da Silva Gorgulho, Ivo Storniolo e Ana Flora Anderson. 9 reimpressão. São Paulo: Paulus, 2013.

BORCHARDT, Francis. Influence and power: the types of authority in the process of scripturalization. Scandinavian Journal of the Old Testament, vol. 29, n. 2, p. 182-196, 2015.

CHRISTENSEN, Duane L. Josephus and the twenty-two-books canon of Sacred Scriptures. JETS, vol. 29, n. 1, p. 37-46, 1986.

COHEN, Shaye J. D. The significance of Yavneh and other essays in Jewish hellenism. Tübingen: Mohr Siebeck, 2010. (Texts and Studies in Ancient Judaism, 136).

DIEZ MACHO, Alejandro. Introduccion general a los Apocrifos del Antiguo Testamento. Con la colaboración de Maria Angeles Navarro y Miguel Perez Fernandez. Madrid: Ediciones Cristandad, 1984. (Apocrifos del Antiguo Testamento, 1).

DORIVAL, Gilles. Has the category of "Deuterocanonical Books" a Jewish origin?. In: XERAVITS, Géza G. Xeravits; ZSENGELLÉR, Jószef (Ed.). The Books of the Maccabees: history, theology, ideology. Papers of the Second International Conference on the Deuterocanonical Books, Pápa, Hungary, 9-11 June, 2005. Leiden; Boston: Brill, 2007, p. 1-10.

EMMET, C. W. 3 Maccabees. In: CHARLES, R.H. (Ed.). The Apocrypha and Pseudepigrapha of the Old Testament. Oxford: Oxford University Press, 1913, p. 155-173 (I).

FERNANDÉZ MARCOS, Natalio. Las traduciones en la antigüedad. Sefarad - Revista de Estudios Hebraicos y Sefardies, Madrid, vol. 67, n. 2, p. 263-282, julio-diciembre 2007.

GOLDSTEIN, Jonathan A. I Maccabees: a new translation with introduction and commentary by Jonathan A. Goldstein. Garden City: Doubleday \& Company, 1976. (The Anchor Bible).

GOLDSTEIN, Jonathan A. II Maccabees: a new translation with introduction and commentary by Jonathan A. Goldstein. New York: Doubleday, 1983. (The Anchor Bible).

GOODMAN, Martin. Introduction to the Apocrypha. In: BARTON, John Barton; MUDDIMAN, John (Ed.). The Oxford Bible Commentary. Oxford: Oxford University Press, 2001, p. 617-626.

GREENSPAHN, Frederick E. Why prophecy ceased. JBL, Atlanta, vol. 108, n. 1, p. 37-49, 1989.

JOOSTEN, Jan. Legal Hermeneutics and the Tradition Underlying the Septuagint. In: KRAUS, Wolfgang; VAN DER MEER, Michaël N.; MEISER, Martin. (Eds.). XV Congress of the International Organization for Septuagint and Cognate Studies, Munich 2013. Atlanta: SBL Press, 2016. (Septuagint and Cognate Studies, 64), p. 551-559.

LANGE, Armin. 2 Maccabees 2:13-15: library or canon?. In: XERAVITS, Géza G. Xeravits; ZSENGELLÉR, Jószef (Eds.). The Books of the Maccabees: history, theology, ideology. Papers of the Second International Conference on the Deuterocanonical Books, Pápa, Hungary, 9-11 June, 2005. Leiden; Boston: Brill, 2007, p. 155-167.

LEWIS, Jack P. Jamnia (Jabneh), Council of. In: FREEDMAN, David Noel (Ed.). Anchor Bible Dictionary. New York: Doubleday, 1992. p. 634-637 (III).

LEWIS, Jack P. What do we mean by Jabneh? Journal of Bible and Religion, vol. 32, n. 2, apr. p. 125-132, 1964.

LIM, Thimoty H. An alleged reference to the tripartite division of the Hebrew Bible. Revue de Qumrân, vol. 77, p. 23-37, 2001. 
LIM, Thimoty H. The formation of the Jewish canon. New Haven: Yale University Press, 2013. [LXX] SEPTUAGINTA. Id est VT graece iuxta LXX interpretes edidit Alfred Rahlfs. Editio altera quam recognovit et emendavit Robert Hanhart. Duo volumina in uno. Stuttgart: Deutsche Bibelgesellschaft, 2011. [Sociedade Bíblica do Brasil]

MOMigliAnO, Arnaldo. Alien wisdom: the limits of hellenization. Cambridge: Cambridge University Press, 1975a.

MOMigLIANO, Arnaldo. The Second Book of the Maccabees. CPh, Chicago, vol. LXX, n. 2, p. 81-88, April 1975b.

NEUSNER, Jacob. The canon of rabbinic Judaism. In: NEUSNER, Jacob Neusner; AVERY-PECK, Alan J. (Eds.). The Blackwell Companion to Judaism. Malden: Blackwell Publishing, 2003, p. 93-111. (Blackwell Companions to Religion).

NICKELSBURG, George W. E. 1 and 2 Maccabees - Same story, different meaning. Concordia Theological Monthly, vol. 42, n. 8, p. 515-526, 1971.

OESTERLEY, William Oscar Emil. An introduction to the Books of the Apocrypha. New York: The Macmillan Company, 1935.

PATTERSON, Stephen J. Apocrypha. In: FREEDMAN, David Noel (Ed.). Anchor Bible Dictionary. New York: Doubleday, 1992, p. 292 (I).

RUPPENTHAL NETO, Willibaldo. Introdução à teologia de 1 Macabeus. Teologia e espiritualidade, Curitiba, vol. 4, n. 7, p. 71-90, 2017.

RUPPENTHAL NETO, Willibaldo. O relato de Hecateu de Abdera sobre os judeus. Hypnos, São Paulo, vol. 41, 2. sem., p. 166-192, 2018.

SCHORCH, Stefan. The libraries in 2 Macc 2:13-15, and the Torah as a public document in second century BC Judaism. In: XERAVITS, Géza G. Xeravits; ZSENGELLÉR, Jószef (Eds.). The Books of the Maccabees: history, theology, ideology. Papers of the Second International Conference on the Deuterocanonical Books, Pápa, Hungary, 9-11 June, 2005. Leiden; Boston: Brill, 2007, p. 169-180.

SCHWARTZ, Daniel R. 2 Maccabees. Berlin; New York: Walter de Gruyter, 2008. (Commentaries on Early Jewish Literature).

SOMMER, Benjamin D. Did prophecy cease? Evaluating a reevaluation. JBL, Atlanta, vol. 115, n. 1, p. 31-47, 1996.

STEMBERGER, Günter. The Maccabees in rabbinic tradition. In: GARCÍA MARTÍNEZ, F.; HILHORST, A.; LABUSCHAGNE, C. J. (Eds.). The Scriptures and the scrolls. Studies in Honour of A. S. Van der Woude on the Occasion of his $65^{\text {th }}$ Birthday. Leiden; New York; Köln: Brill, 1992, p. 193-203.

TROMP, Johannes. The formation of the Third Book of the Maccabees. Henoch, vol. XVII, p. 311-328, 1995.

VANDERKAM, James C. An introduction to early Judaism. Grand Rapids: Eerdmans, 2001a.

VANDERKAM, James C. Questions of canon viewed through the Dead Sea Scrolls. Bulletin for Biblical Research, vol. 11, n. 2, 2001b, p. 269-292.

VAN DER KOOIJ, Arie. The canonization of ancient Books Kept in the Temple of Jerusalem. In: VAN DER KOOIJ, A.; VAN DER TOORN, K. (Eds.). Canonization \& decano- 
nization. Papers presented to the International Conference of the Leiden Institute for the Study of Religion (LISOR) held at Leiden 9-10 January 1997. Leiden: Brill, 1998, p. 17-40. WARREN-ROTHLIN, Andy. The accretion of canons in and around Qumran. The Bible Translator, vol. 67, n. 2, p. 120-136, 2016.

YOUNG, Ian. The stabilization of the biblical text in the light of Qumran and Masada: a challenge for conventional Qumran chronology? Dead Sea Discoveries, vol. 9, n. 3, p. 364390, 2002.

Submetido em: 1-2-2019

Aceito em: 11-6-2019 